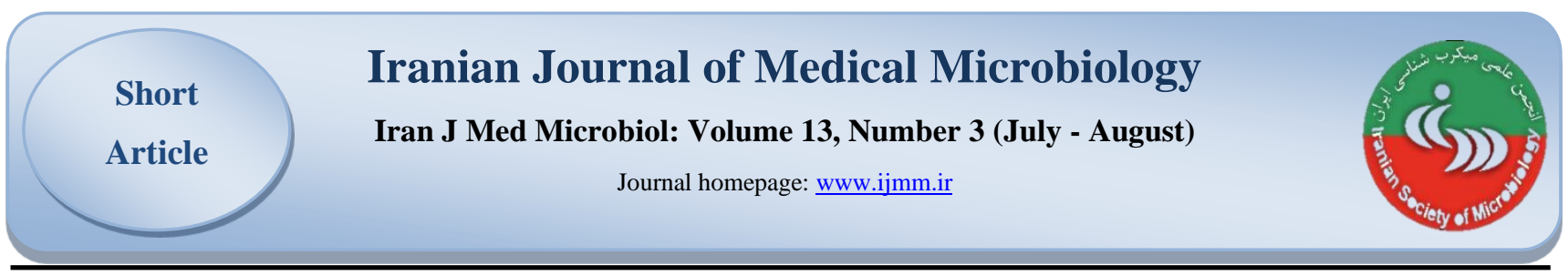

\title{
The Effect of Matricaria chamomilla Alcoholic Extract on Phenotype Detection of Efflux Pumps of Methicillin Resistant Staphylococcus aureus (MRSA) Isolated from Skin Lesions
}

\author{
Pargol Abdi ${ }^{1}$, Maasoumeh Mahdavi Ourtakand ${ }^{2 *}$, Sahar Honarmand Jahromy ${ }^{1}$ \\ 1. Department of Microbiology, Faculty of Biological Sciences, Varamin- Pishva Branch, Islamic Azad University, Varamin, Iran \\ 2. Department of Biology, College of Biological Sciences, Varamin-Pishva Branch, Islamic Azad University, Varamin, Iran
}

\section{Article Information}

\section{Article Subject:}

Antimicrobial Agents

doi) 10.30699/ijmm.13.3.220

Corresponding author:

Maasoumeh Mahdavi Ourtakand Department of Biology, College of Biological Sciences, Varamin-Pishva Branch, Islamic Azad University, Varamin, Iran

Email:

masumehmahdavi@gmail.com

Use your device to scan and read the article online

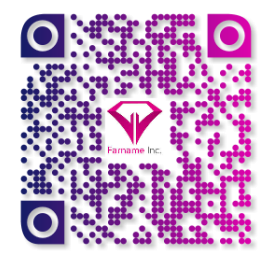

\section{Abstract}

Background and Aims: Methicillin-resistant Staphylococcus aureus strains are resistant to many antibiotics. One of the major causes of drug resistance in bacteria is the efflux pumps. Matricaria chamomilla is a plant that is effective in treating skin diseases. The aim of this study was to investigate the effect of M. chamomilla alcoholic extract on phenotype detection and inhibition of efflux pumps of methicillin resistant S. aureus (MRSA) isolated from skin lesions.

Materials and Methods: The study was performed on 30 strains of $S$. aureus isolates collected from skin infections. The Strains of MRSA were detected by cefoxitin disc diffusion test. M. chamomilla alcoholic extract was prepared and its MIC was obtained against MRSA strains by broth microdilution method. Cartwheel method was used to study phenotypic activity of efflux pump. The effect of $M$. chamomilla extract was investigated on strains with active efflux pumps.

Results \& Conclusion: from 30 strains of isolated S. aureus, $33.3 \%$ were methicillinresistant. Three strains (10\%) had active efflux pump, among which one strain was detected as MRSA. MIC of $M$. chamomilla extract was between 128-64 $\mu \mathrm{g} / \mathrm{ml}$. With the effect of $1 / 2$ MIC of M. chamomilla extract on the strains with a strong efflux pumps, the two stains were reported as non-actives. $M$. chamomilla extract on the MRSA strain efflux pump was ineffective. Antimicrobial effect of $M$. chamomilla extract was confirmed on MRSA isolated from skin lesions.

Keywords: Matricaria chamomilla, Phenotype, MRSA, Antimicrobial Drug Resistance, Antimicrobial Agents.

Received: 2017/10/23

Accepted: 2019/05/16

Available online: 2019/08/23

Copyright $\odot$ 2019. This is an open-access article distributed under the terms of the Creative Commons Attribution- 4.0 International License which permits Share, copy and redistribution of the material in any medium or format or adapt, remix, transform, and build upon the material for any purpose, even commercially.

How to cite this article:

Abdi P, Mahdavi Ourtakand M, Honarmand Jahromy S. The Effect of Matricaria chamomilla Alcoholic Extract on Phenotype Detection of Efflux Pumps of Methicillin Resistant Staphylococcus aureus (MRSA) Isolated from Skin lesions. Iran J Med Microbiol. 2019; 13 (3) :220-231

Download citation:

$\underline{\text { BibTeX }}|\underline{\text { RIS }}| \underline{\text { EndNote }}|\underline{\text { Medlars }}| \underline{\text { ProCite }}|\underline{\text { Reference Manager }}| \underline{\text { RefWorks }}$

Send citation to:

Mendeley 2 Zotero $(\mathbb{H}$ RefWorks 


\section{Introduction}

Staphylococcus aureus, in particular, methicillin resistant $S$. aureus (MRSA), is one of the main causes of hospital infections and communityacquired infections, with high morbidity and mortality rates worldwide (1). S. aureus infections cause difficult conditions to care and treat ulcers, damaged skin and soft tissue (2). MRSA are the principle cause of colonization and infection in the acute and chronic ulcerous lesions (4). Efflux Pump is one of the mechanisms of these bacteria in order to show antibiotic resistance (5). Many studies have investigated the inhibitory effect of some plant essential oils on efflux pumps in S. aureus strains (810). The simple way to evaluate the phenotypic effect of the efflux pump is the use of EtBr-Agar, which takes advantage agar plates and contains EtBrincreasing concentrations, which is known as the EtBr-Agar or cartwheel method $(11,12)$. Inside the plants, some compounds act in association with the antimicrobial agents, as they are responsible for disrupting the function of the efflux pumps in plant pathogens (7). Some plants have been involved in the treatment of skin diseases, and their effects have been proven like Matricaria chamomilla belongs to Asteracae family. This plant has antimicrobial and anti-inflammatory effects $(\mathbf{1 3 , 1 4 )}$. The aim of this study was to investigate the effect of $M$. chamomilla alcoholic extract on phenotypes of MRSA strains isolated from skin lesions.

\section{Materials and Methods}

This study was performed on 30 samples of $S$. aureus collected from patients with skin lesions who referred to Shariati hospital in Tehran in the spring of 2017. The samples were characterized by different biochemical tests, including Gram stain, catalase, coagulase, DNase and mannitol fermentation, which led to identification and isolation. The antibiotics resistance of strains was assessed by disk diffusion method. To detect the phenotypic resistance of methicillin-resistant $S$. aureus, the susceptibility of the bacterial specimen to Cefoxitin disc $(30 \mu \mathrm{g})$ in the Muller Hinton Culture medium was investigated. The M. chamomilla capitols were collected from Ardebil city and after taxonomic identification, they dried at $25^{\circ} \mathrm{C}$ in the shade and then powdered by the mechanical mill. The powder obtained from chamomilla capitols was mixed with $80 \%$ ethanol and then placed in a Soxhlet extractor. $M$. chamomilla alcoholic extract was prepared and MIC of it was obtained against MRSA strains by broth microdilution method. In order to investigate the activity of the efflux pumps phenotypically, all stains were evaluated by ethidium bromide containing agar using Cartwheel method (16). After identification of the strains with an activated efflux pump, the effect of $M$. chamomilla extract on the inhibitory activity of the pump was investigated. For this purpose, the dilutions $1 / 2$ and $1 / 4$ of the MIC of the extract were applied (according to the MIC level of each strain).

\section{Results and Conclusion}

According to the results, the highest antibiotic resistance of $S$. aureus strains was respectively related to penicillin $(83.3 \%)$, cefoxitin $(33.3 \%)$, while the lowest resistance belongs to chloramphenicol which reported $(3.3 \%)$. among $30 \mathrm{~S}$. aureus strains, 10 strains (33.3\%) were MRSA (Fig. 1). The results of this study and the comparison with other reports on the prevalence of methicillin-resistant strains indicate increased methicillin-resistant strains, one of the reasons of which has been due to the excessive use of antibiotics in recent years. MIC of M. chamomilla extract was tested for the studied strains and result obtained between 128-64 $\mu \mathrm{g} / \mathrm{ml}$. The antimicrobial effect of $M$. chamomilla extract and essential oil against a range of bacteria and fungi has been investigated and confirmed $(20,21)$.

In this study, ethidium bromide cartwheel assay was performed to detect the phenotypic activity of the efflux pump in $S$. aureus strains. Based on the results of this study, three strains were highly active among 30 strains, and did not exhibit fluorescence in all dilutions of ethidium bromide, which means they had strong efflux pumps. Among these three strains, one was MRSA. With the effect of $1 / 2$ MIC of $M$. chamomilla extract on the strains with a strong efflux pumps, the two stains were reported as non-actives. M. chamomilla extract on the MRSA strain efflux pump was ineffective. (Figs. 2 and 3). Evaluation of 1/4 MIC of $M$. chamomilla extract had no effect on efflux pump activity. Khan et al. (2006) showed that the piperine, a plant alkaloid of the Piperaceae family, at a concentration of $25 \mathrm{mg} / \mathrm{L}$ reduced twofold the MIC of $S$. aureus compared to the ciprofloxacin antibiotic. This decrease in MIC is due to the increase in the antibiotic concentration of ciprofloxacin in the bacterium, because of the inhibitory effect of the efflux pumps (28). Smith et al. used the Totarol isolated from the immature cones of 
Chamaecyparis nootkatensis to inhibit the NorA $S$. aureus pump. They used MIC analysis of ethidium bromide in combination with Totarol to evaluate pump inhibition and reported that the compound studied had antimicrobial activity and also inhibited the NorA pump (26).

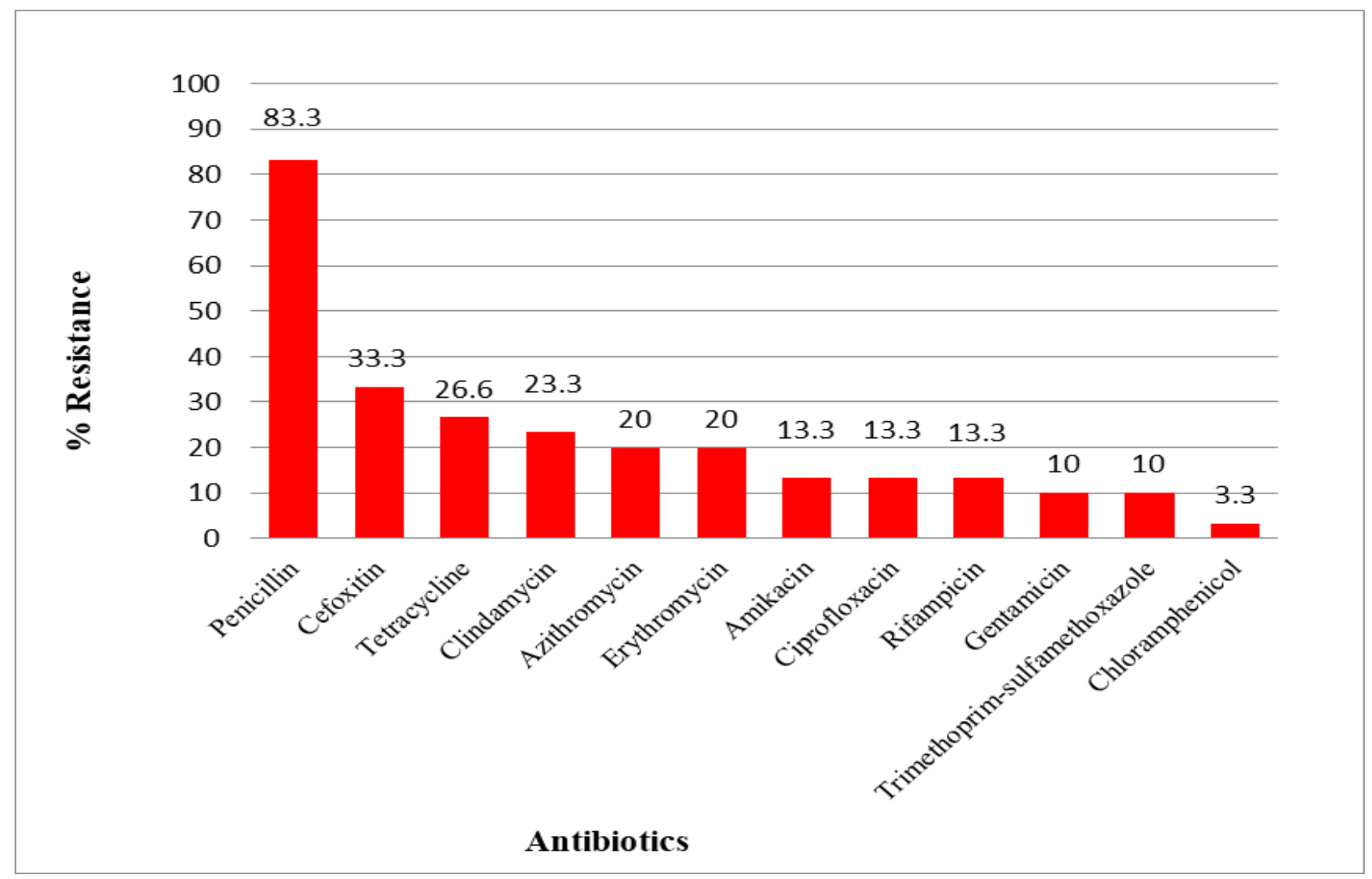

Figure 1. Antibiotic resistance patterns of Staphylococcus aureus strains

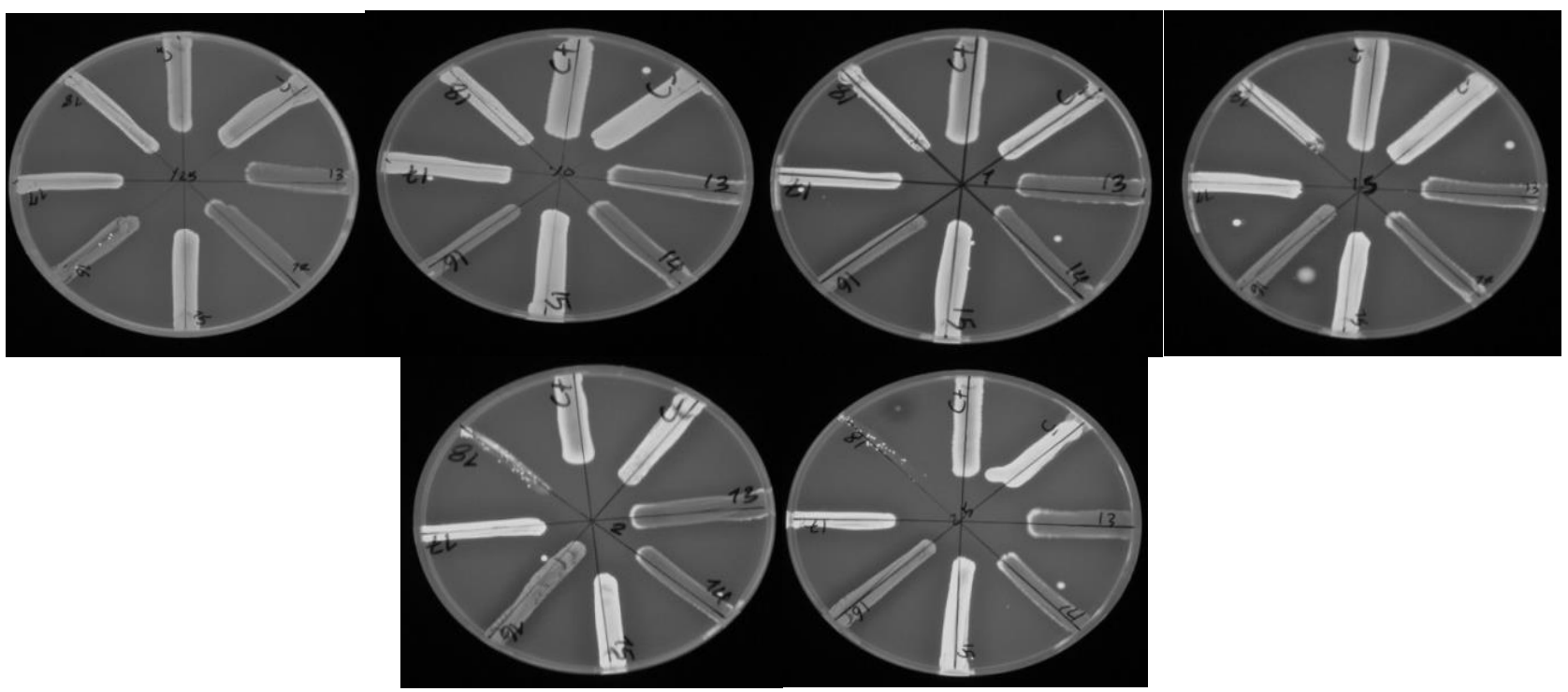

Figure 2. Fluorescent plates containing concentrations of 0.25 to $2.5 \mathrm{~g} / \mathrm{L}$ of ethidium bromide and microbial suspension of Staphylococcus aureus strains: strains 13,14 and 16 did not show fluorescent activity in all dilutions of ethidium bromide and became known as strong strains. Each growth line belongs to one isolate. Transparent culture lines indicate inactivation of the effluent pump and opaque cultivation lines indicate that the effluent pump system is active. Strain 14 was MRSA. 


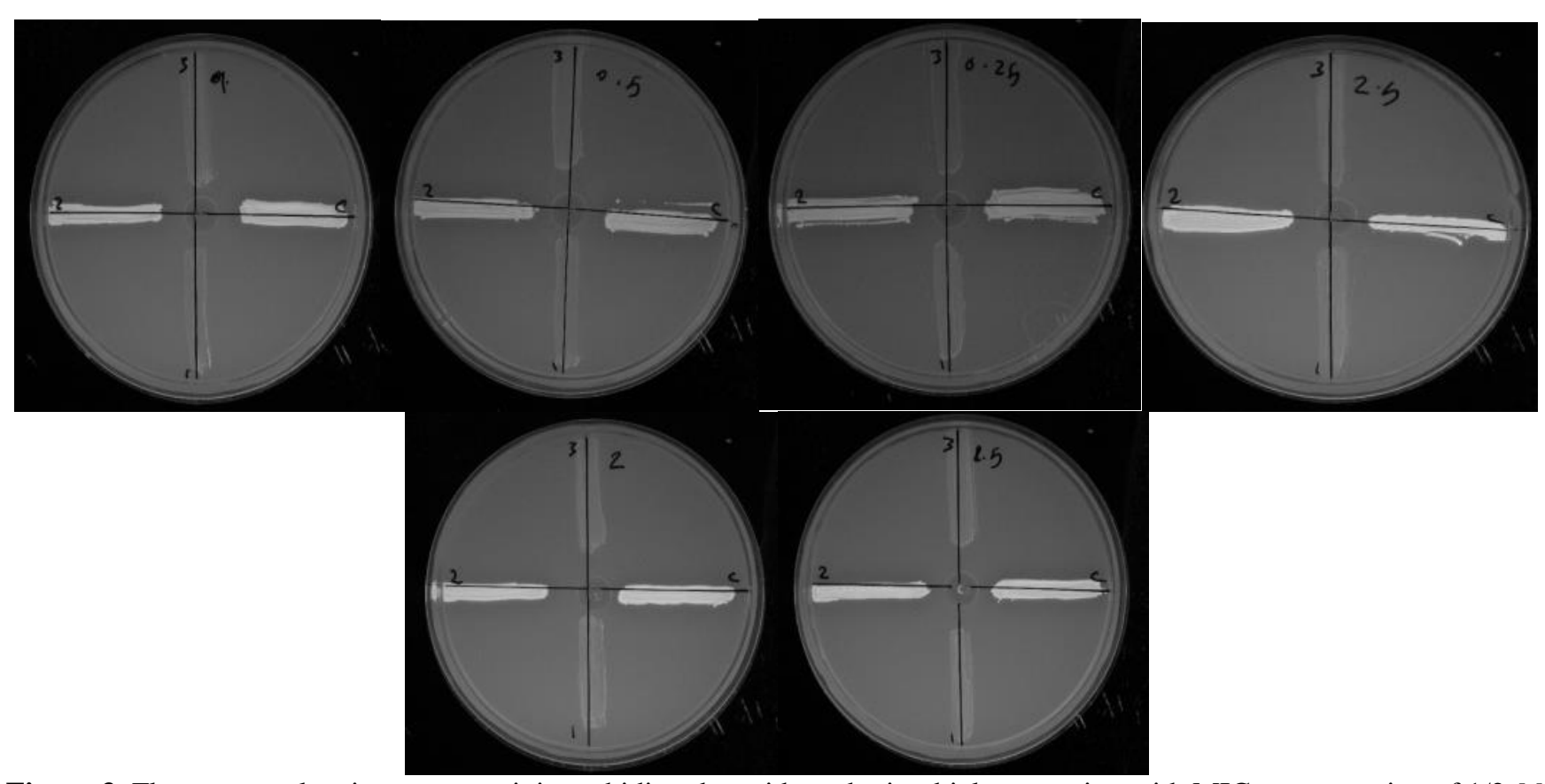

Figure 3. Fluorescent plate images containing ethidium bromide and microbial suspension with MIC concentration of $1 / 2 M$. chamomilla extract of each strain: strains 13 and 16 showed fluorescent activity in all dilutions of ethidium bromide and were identified as inactive. MRSA strain 14 remained active.

There are major challenges to find new inhibitors. Considering the antimicrobial effects of plant compounds on inhibiting efflux pump, bacteria that were initially resistant to antibiotics can be sensitive later and, if this approach is successful in the future, it could be considered as an important alternative in the treatment of some infections caused by drug-resistant strains. It is also important to determine the expression level of these genes encoding efflux pumps among phenotypically active isolates, and that the role of synergy between efflux pumps and other antibiotic resistance mechanisms, to achieve this high resistance level, should not be ignored. Further studies are suggested to investigate the genotypic expression of efflux pumps in methicillin-resistant $S$. aureus strains.

\section{Acknowledgements}

The authors would like the staff of Microbiology Research Laboratory of Azad Islamic University, Varamin branch and also Mr. Omid Hosseini, the technician of the Research Laboratory of Shahid Beheshty University. The ethical code for this research was IR.IAU.VARAMIN.REC.1396.3.

\section{Conflict of Interest}

The authors reported no conflict of interest. 


\section{بررسى اثر عصاره الكلى بابونه بر بروز فنوتيِى يميّهاى تراوشى سويه هاى استافيلوكوكوس اورئوس مقاوم بـ متى سيلين جدا شده از ضايعات يوستى

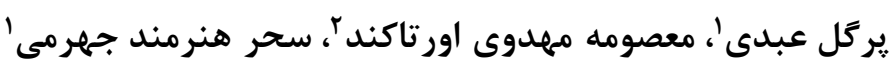

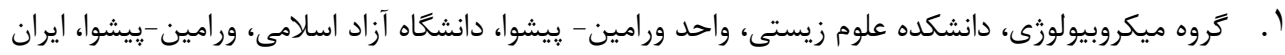

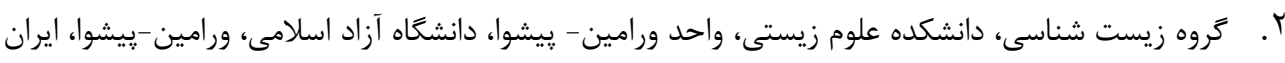

\section{جكبين}

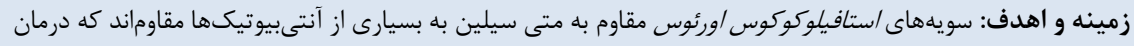

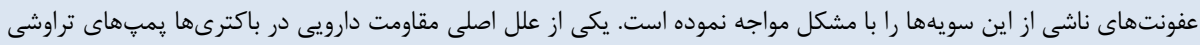

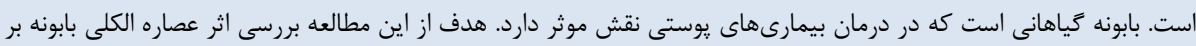

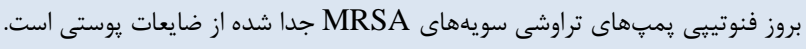

مواد و روش كار: مطالعه روى · ب سويه /ستافيلوكوكوس /ورئوس جدا شده از نمونهاى عفونتهاى يوستى انجام شد.

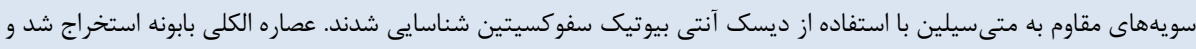

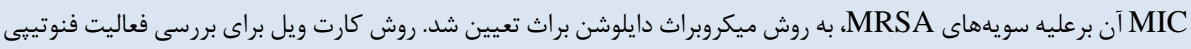

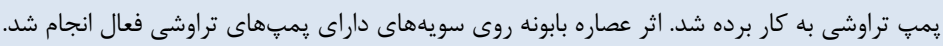
يافته ها و بحث: از بين سويه /ستافيلوكوكوس /ورئوس مورد بررسى، ب/Tr/\% سويهها مقاوم به متىسيلين بودند. سه سويه

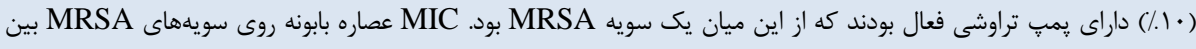

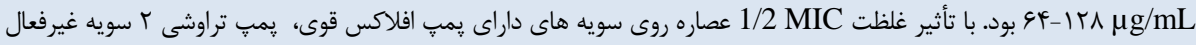

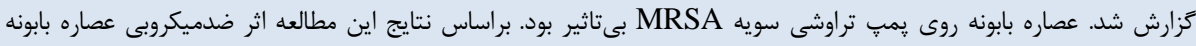

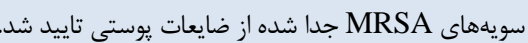
كليد وازهها: بابونه، فنوتيت، MRSA ، مقاومت آنتى بيوتيكى، مواد ضد ميكروبى كيىرايت (؟ مجله ميكروبشناسى بزشكى ايران: دسترسى آزاد؛ كيى بردارى، توزيع و نشر براى استفاده غيرتجارى با ذكر منبع آزاد است.

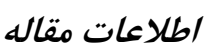

تاريخجهُ مقاله

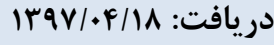

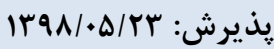

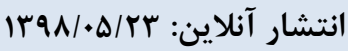

موضوع: مواد ضد ميكروبى

\section{IJMM1398;13(3): 220}

نويسندهُ مسئول:

معصومه مههدوى اور تاكند

استاديار، تروه زيست شناسى، دانشكده

علوم زيستى، واحد ورامين- يُيشوا، دانشكاه

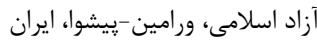

يست الكترونيك: asumehmahdavi@gmail.com

مقدمه

استافيلوكوكوس /ورئوس مقاوم به متى سيلين (MRSA) مى توانند

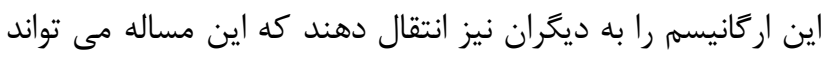

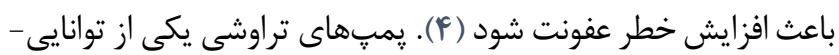

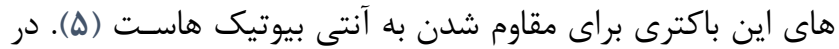
طى اين فرآيند باكترى، تركيبات خارج سلولى سمى مانند داروها،

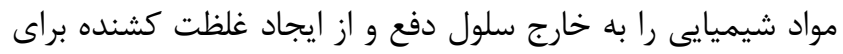

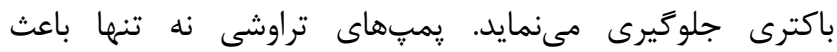
افزايش MIC آنتىبيوتيكها بلكه با كاهش غلظت دارو در داخل سلول منجر به ايجاد سويههاى موتانت مقاوم در باكترىها مى

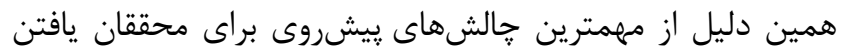
راهى براى مهار سيستمهاى يمب تراوشى است (ع). در داخل كَياهان تركيباتى به صورت همكار با مواد ضد ميكروبى عمل مى كنند
استافيلوكوكوس اورئسوس از عوامل مهم در عفونتهاى بيمارستانى است و در بسيارى از موارد از عفونتهاى يوستى منشاء

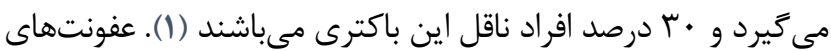
استافيلوكوكوس /ورئوس، مراقبت و درمان زخمها، يوست و نسج نرم

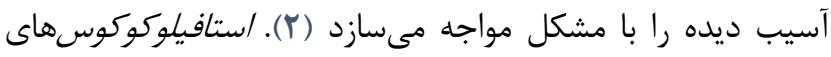

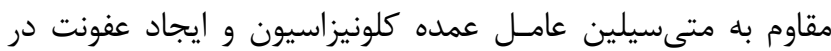
زخمهاى حاد و مزمن بافت نرم مىباشند. مقاومت به متى سيلين نشاندهندة مقاومت متى سيلين نشاندهندة مقاومت به تمام سفالوسيورينها و ينىسيلينهاى مقاوم به ينىسيليناز است. بيماران آلوده با/ستافيلوكوكوس /ورئوس مقاوم به متىسيلين (MRSA) مى -

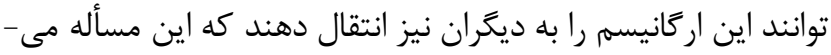
تواند باعث افزايش خطر عفونت شود (ب). بيماران آلوده بان 


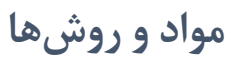 \\ نمونهكيرى و شناسايى باكترىها}

اين مطالعه توصيفى مقطعى روى •r نمونه /ستافيلوكوكوس

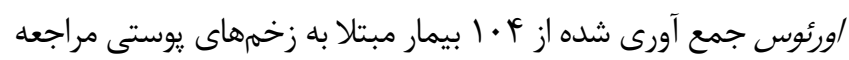

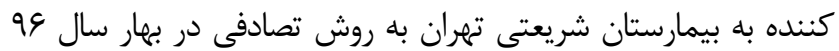

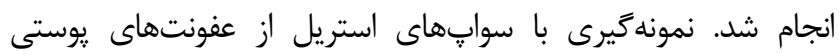
تشخيص داده شده توسط يزشكان متخصص يوست و عفونى انجام شد..

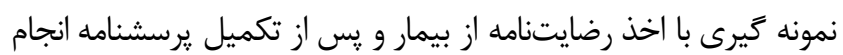
كرفت. نمونه ها توسط تست هاى بيوشيميايى افتراقى شامل رنخ آميزى

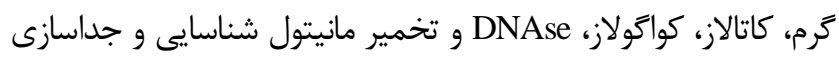

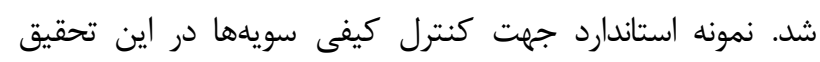
Staphylococcus aureus ATCC 25923

$$
\text { كلكسيون ميكروبى ايران خريدارى شد. }
$$

\section{تست تعيين حساسيت آنتىبيوتيكى و تعيين سويههاى}

MRAS

مقاومت سويههاى مطالعه به TI آنتى بيوتيك و به روش انتشار از ديسك، براساس استانداردهاى CLSI, با استفاده از كشت برروى

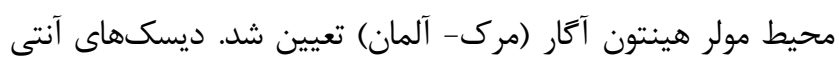

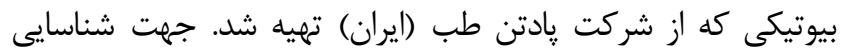
فنوتييى سويههاى استافيلوكوكوس اورئوس مقاوم به متى سيلين،

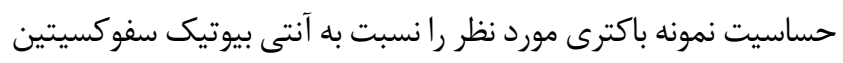

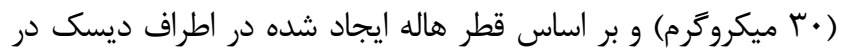

$$
\text { محيط مولر هينتون مورد بررسى قرار گرفت. }
$$

\section{تهييه عصاره الكلى گَياه بابونه}

كايتولهـاى كيـاه بابونهـ (Matricaria chamomilla)

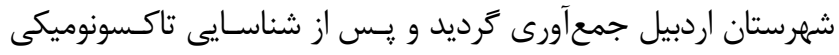

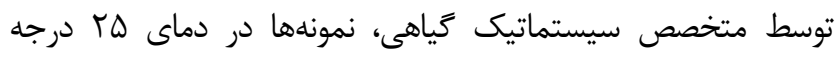

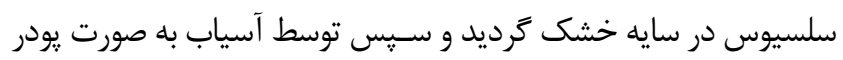

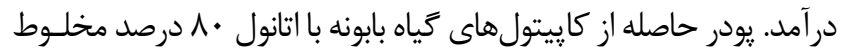

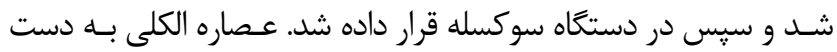

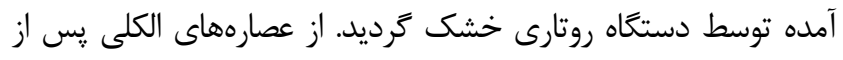
تغليظ در دستخاه تقطير در خلاء در نهايت ب ميلى ليتر عصاره غليظ

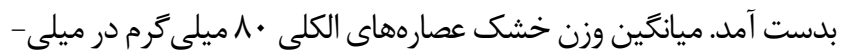
ليتر بود كه با توجه به آن رقتهاى مختلف عصارهها محاسبه شد.
و مسئول مختل كردن عملكرد پِمٍ هاى تراوشى ياتوزنهاى گياهى

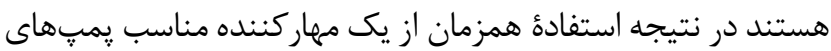
تراوشى به همراه مواد ضد ميكروبى كياهى ممكن است بتوانند

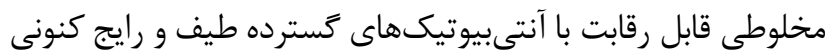
باشد (V) - (V). مطالعات بسيارى اثر مهارى برخى از اسانسهاى گياهى در

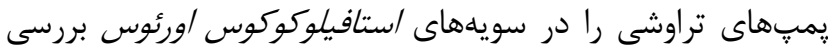

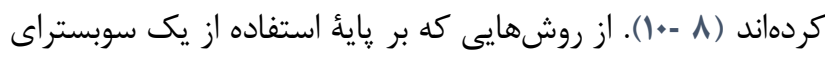
مناسب فعاليت يمبِهاى تراوشى به نام اتيديوم برومايد (EtBr) است،

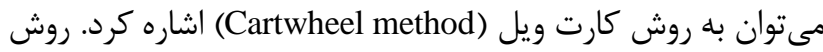

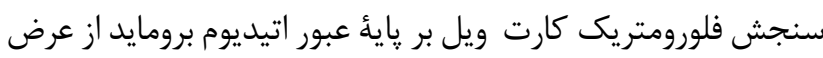

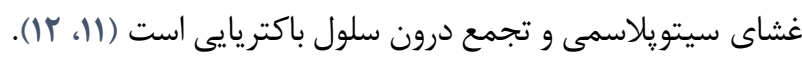

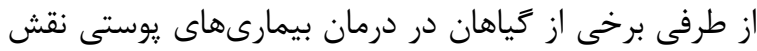

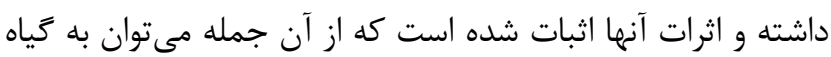
بابونه اشاره كرد. بابونه با نام علمى Matricaria chamomilla، كياهى آنى

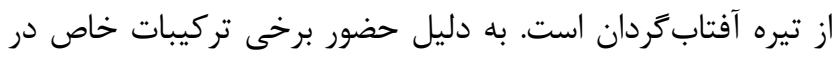
بابونه بر روى آن مطالعات زيادى روى آن انجام كرفته و مشخص شرد شده

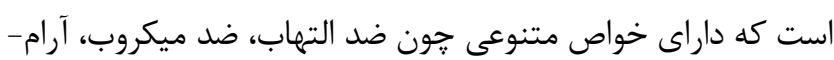

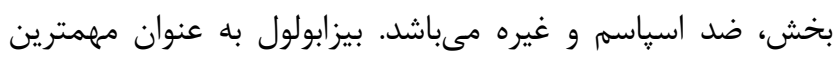
تركيب شيميائى در عصاره اين خياه داراى اثرات ضد ميكروبى است.

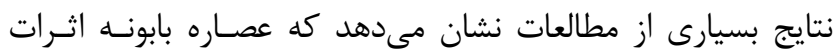

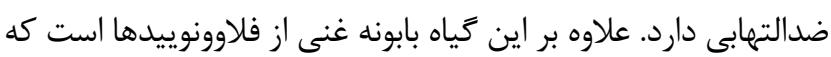

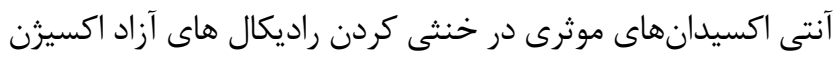

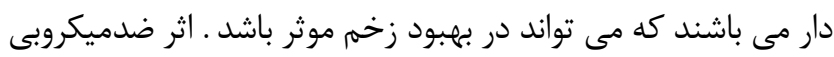

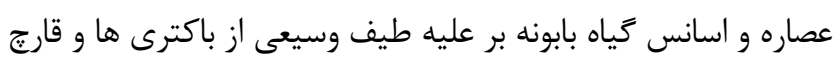
ها هاز جمله , Bacillus, Enterococcus faecalis, Escherichia coli, Listeria innocua, Salmonella enteric, Shigella dysenteria, Staphylococcus aureus, Staphylococcus camorum, Pseudomonas aeruginosa, Streptococcus pyogenes, Aspergillus niger, Candida albicans

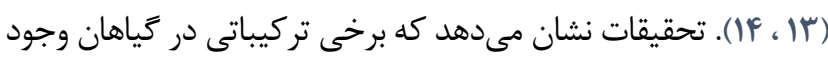

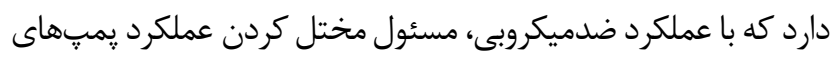

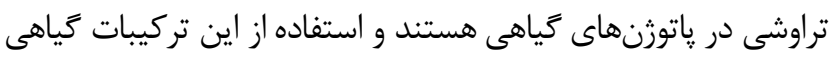

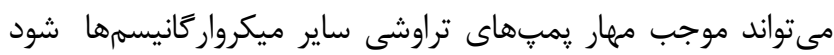

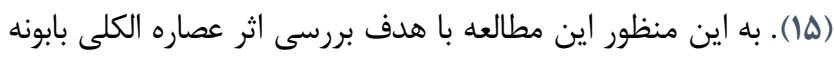

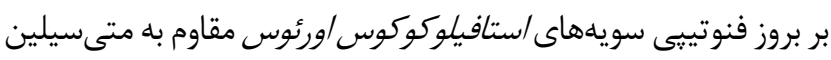
جدا شده از ضايعات يوستى انجام شده است. 
فلوروسنس هر جدايه با دستكاه زل داك (شركت كيازن ساخت ايران) اندازمخيرى شد تا كمترين غلظت اتيديوم برومايد مؤثر بر باكترى

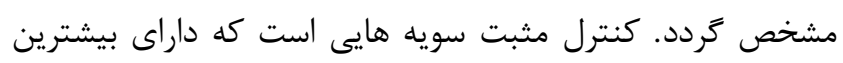
خاصيت فلوروسنس (بيانكر عدم فعاليت افلاكس يا فعاليت

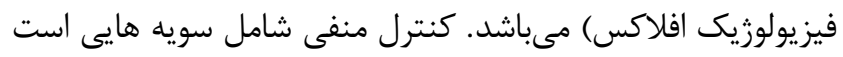

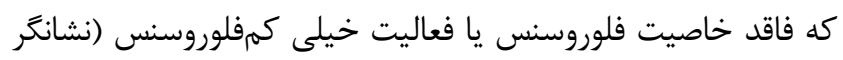
فعال بودن افلاكس) مى باشند (1).

\section{بررسى اثر عصاره بابونه بر فعاليت يمٍهاى تراوشى به} روش كارت ويل

مِ از مشخص شدن سويههاى داراى يمب تراوشى فعال، اثر

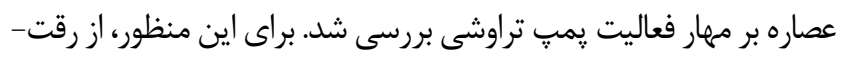
هاى يك دوم و يك جهارم MIC عصاره مورد مطالعه (با توجه ميزان

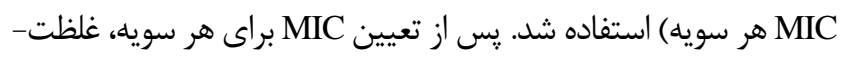

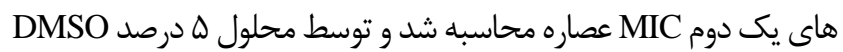
به حجم ..

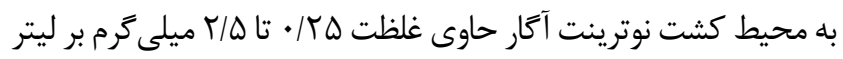

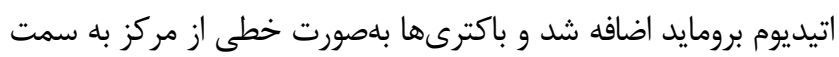

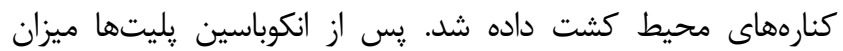
فلوروسنت هر يليت با دستخاه زل داك بررسى شد و سويههايى كه داراى

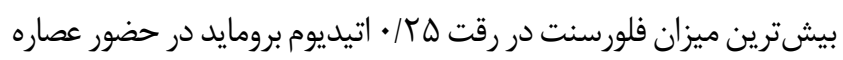
بودند بهعنوان تراوشى فعال در نظر كرفته شدند. سويههايى كه با تأثير

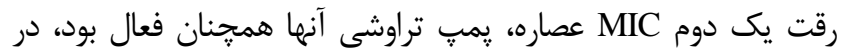

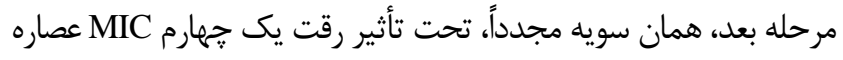

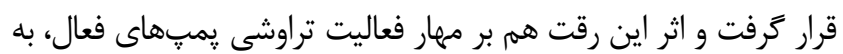

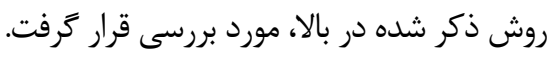

\section{يافتلها و بحث}

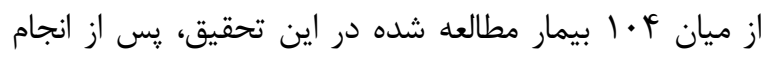

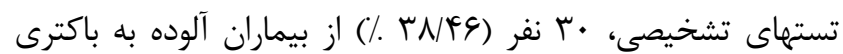

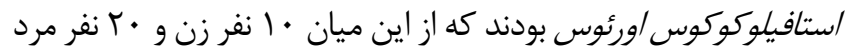

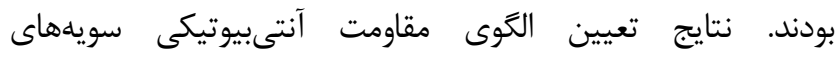

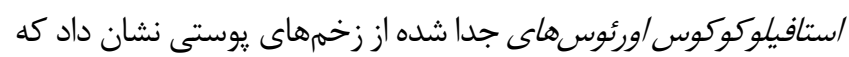

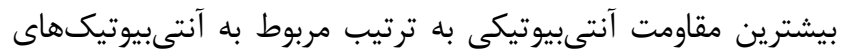

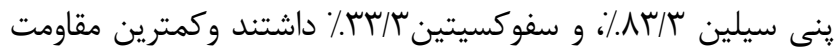

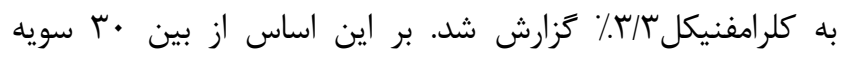

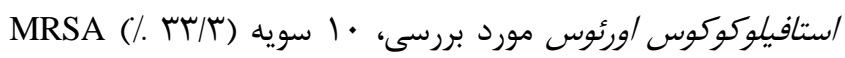

\section{تعيين حداقل غلظت بازدارندكى (MIC) عصاره بابونه}

استوك اوليه عصاره با رقت هIT ميكروگرم بر ميلىليتر توسط محلول ه درصد DMSO رقيق شد تعيين MIC به روش ميكرودايلوشن

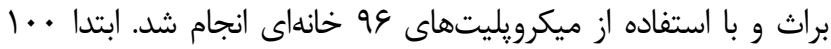

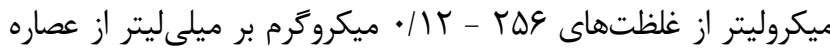

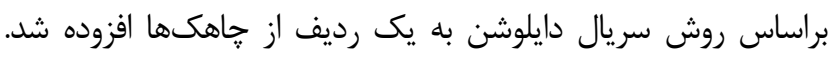
سوسيانسيون ميكروبى كه با نيم مك فارلند برابر شده بود به وسيله محيط كشت مولر هينتون براث به ميزان ..1/1 جهت به دست آوردن

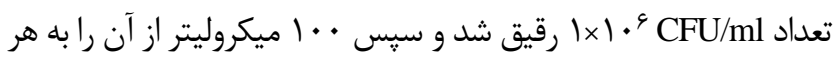

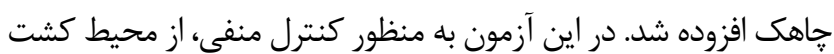
خالى (بدون عصاره و سوسيانسيون ميكروبى) استفاده كرديد. همجنين إنين محنيط سوسيانسيون ميكروبى و محيط كشت بدون عصاره به عنوان كنترل

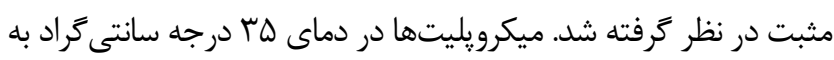

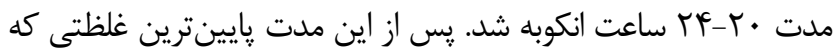

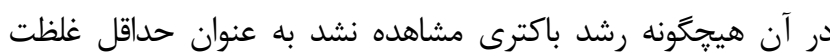
بازدارندگى (MIC) تعيين شد. تمامى اين مراحل براى سويههاى مقاوم

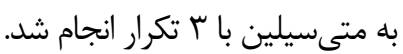

\section{بررسى فنوتيبى فعاليت يֶٍ تراوشى به روش كارت ويل}

بلامنظور بررسى فعاليت پِمٍِهاى افلاكس بلهورت فنوتييى

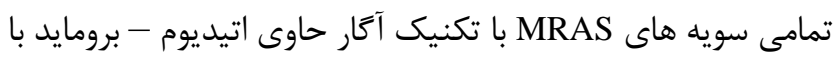
روش كارت ويل مورد بررسى قرار كرفتند. در اين روش كمترين ميزان فلورسنس باكترىها بايد تعيين شود. ابتدا محلول پايه اتيديوم

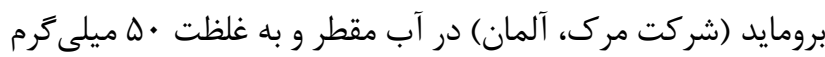
بر ميلىليتر تهيه شده و در دماى أ درجة سانتى گراد نكَهدارى شد. كشت شبانه روزى از سويه هاى مورد بررسى در ه ميلى ليتر محيط

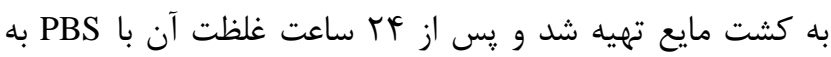
استاندارد ه/ • مك فارلند رسانده شد. يليتهاى حاوى محيط كشت آن نوترينت آكار( شركت مرك، آلمان) همراه با غلظتهاى آنائ اتيديوم

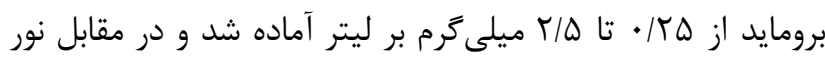

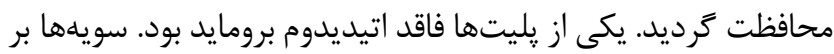

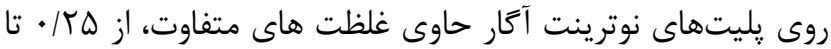

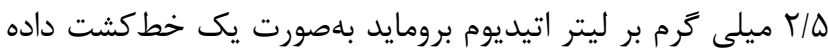

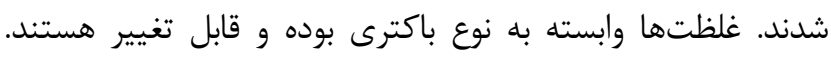
كمترين غلظت ممانعت كننده رشد (MIC) نيز r ميلى كرم در ليتر

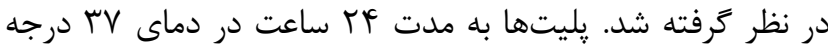

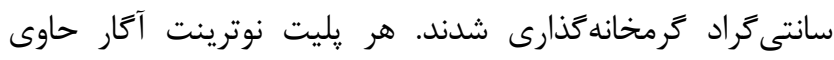

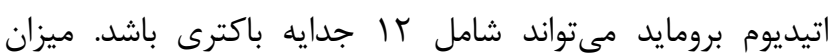


استافيلوكوكوس /ورئوس نقش يمبٍهاى تراوشى است كه مانع از

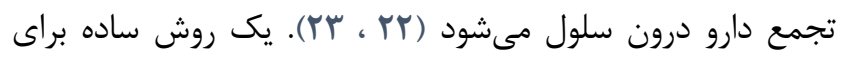

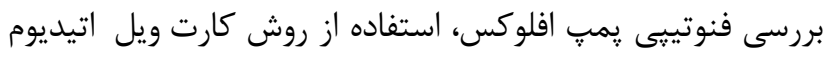

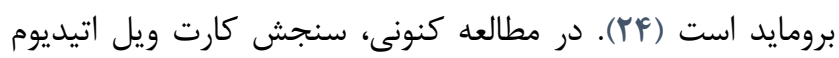

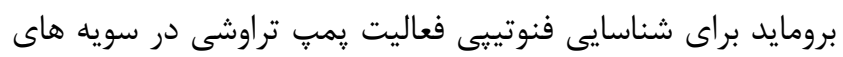

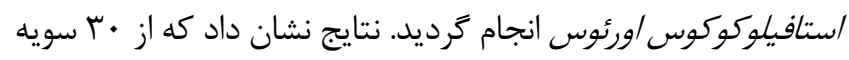

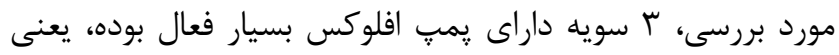

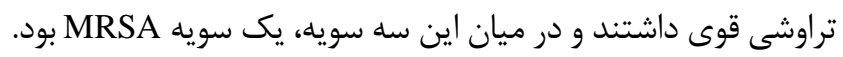

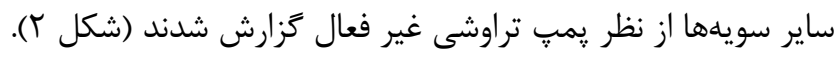

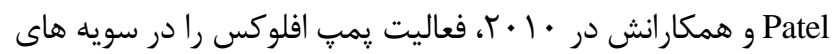

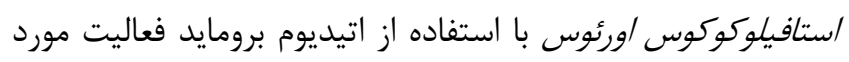

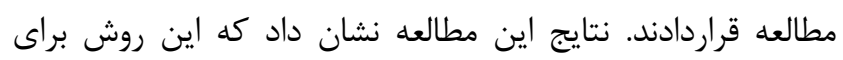

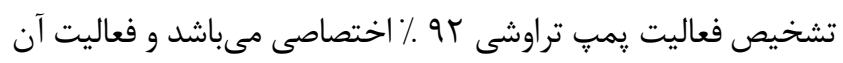
مرتبط با بيان زن NorA مىباشد (rQ T).
بودند (شكل (1). مطالعات مختلفى جهت بررسى ميزان مقاومت آنتى

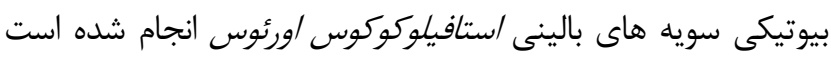
Fagheei-Aghmiyuni . (IV)

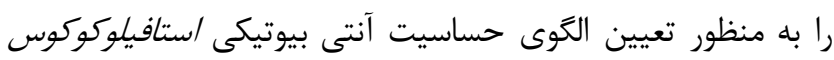

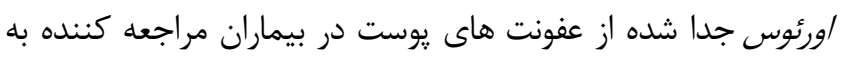
بيمارستان يوست رازى تهران انجام دادند كه نتايج اين تحقيق نشان

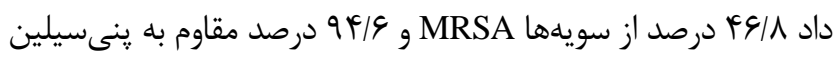

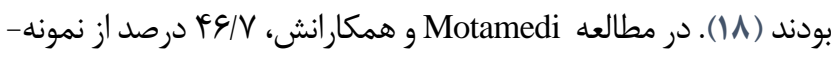
هاى/ستافيلوكوكوس/ورئوس مقاوم به متىسيلين از عفونت يوست جدا شده بود و بيش از \&\& درصد ايزولهها مقاوم به متىسيلين بود (19).

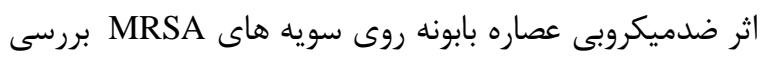

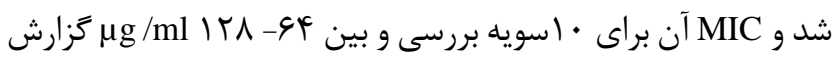
و تاييد شد. اثر ضدميكروبى عصاره و اسانس تياه بابونه بر عليه طيف

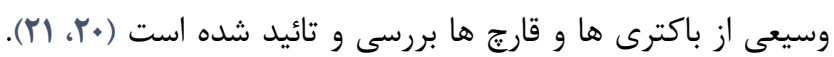
يكى از مكانيسمهاى تائيد شده در مقاومت آنتى بيوتيكى باكترى

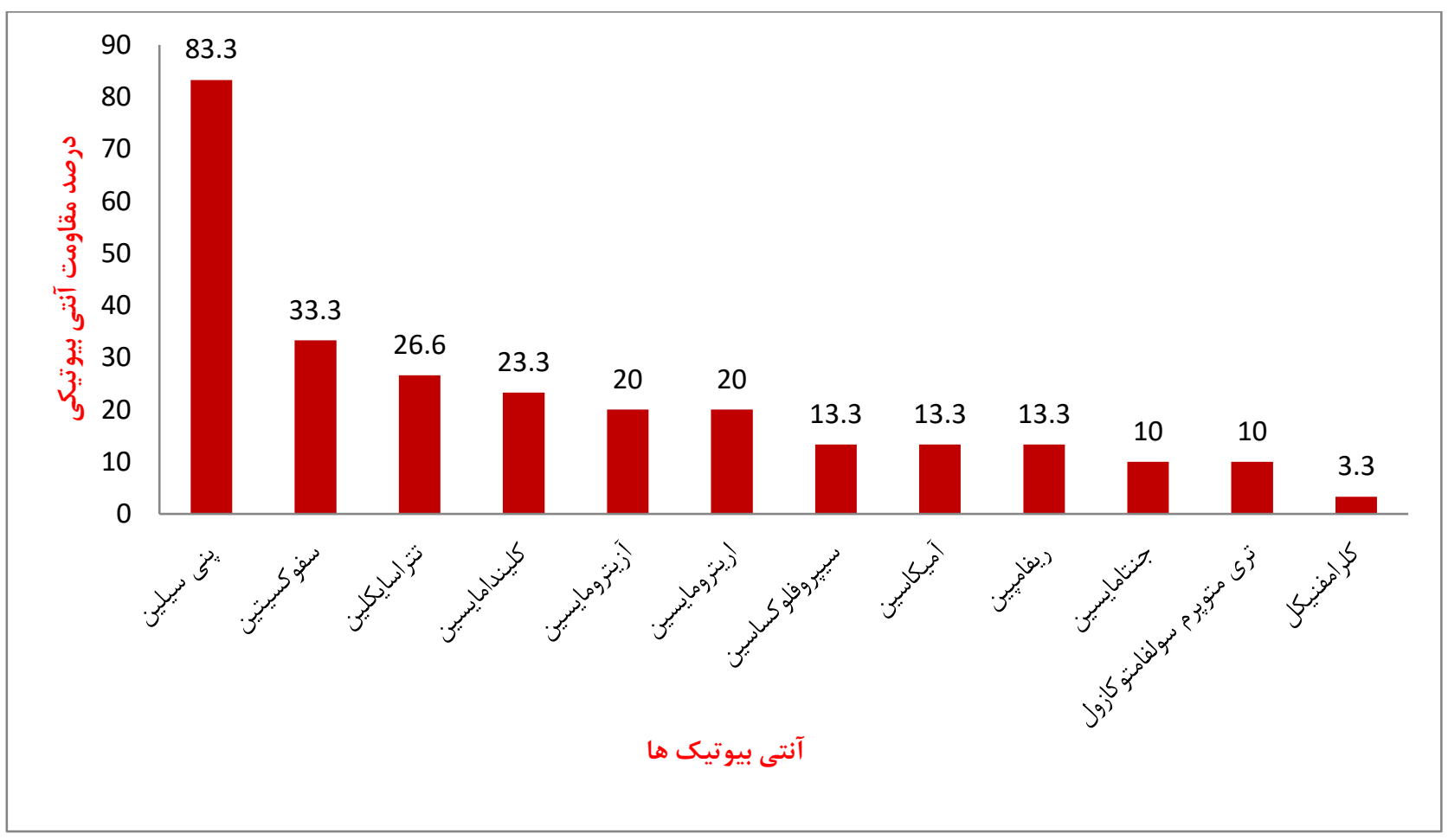

شكل ا: نمودار درصد مقاومت آنتىبيوتيكى سويه هاى/ستافيلوكوكوس/ورئوس 


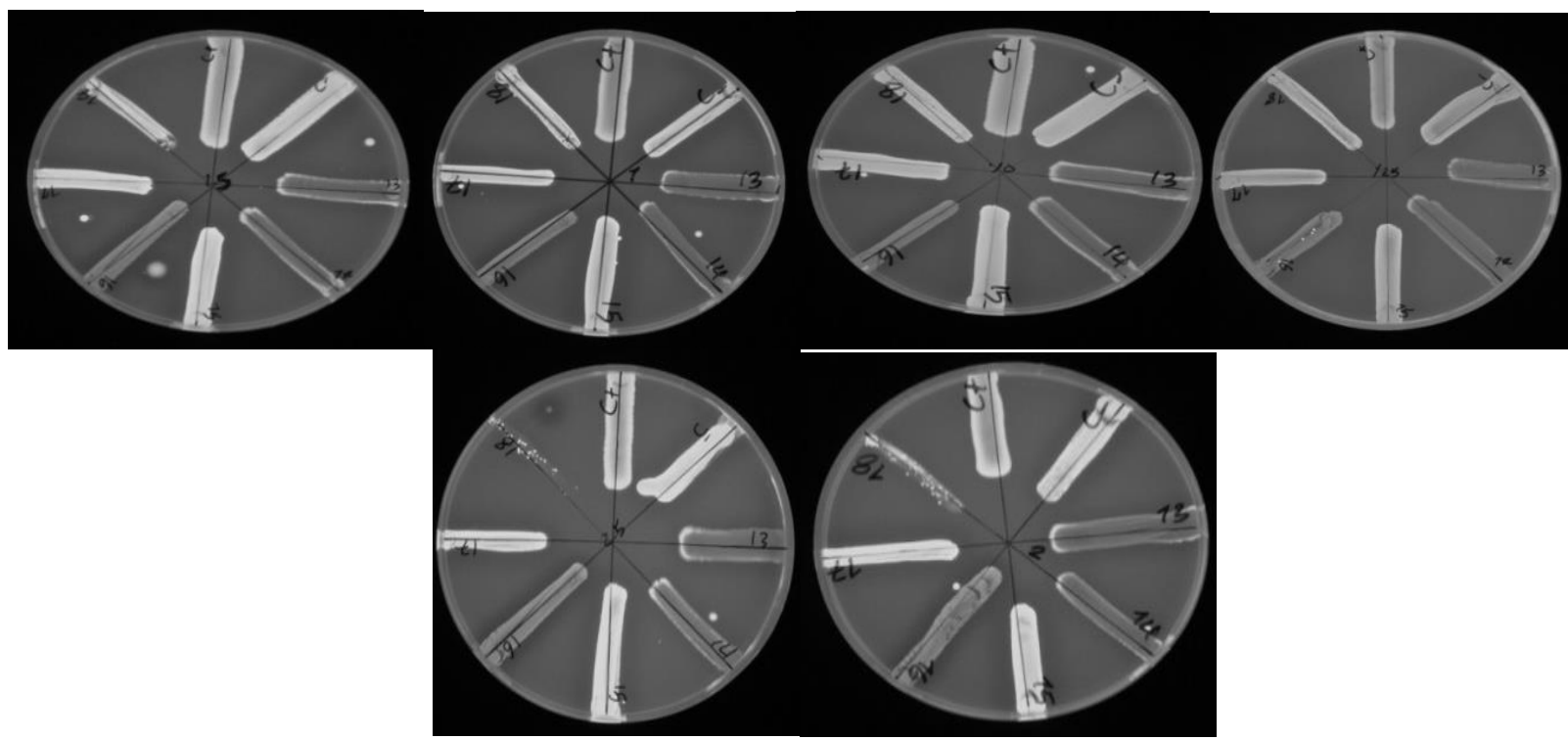

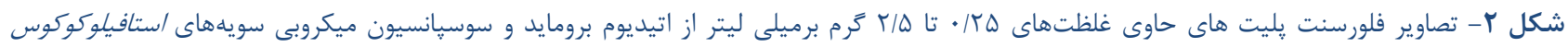

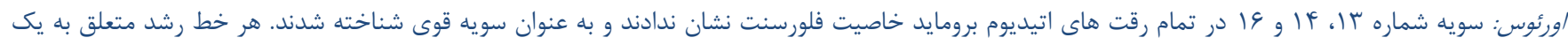

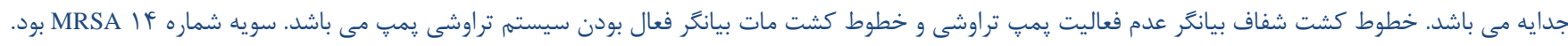

كزارش نمودند كه ماده مورد مطالعه خاصيت ضد ميكروبى دارد و هم

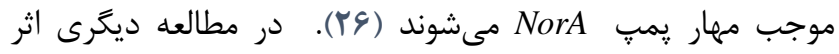

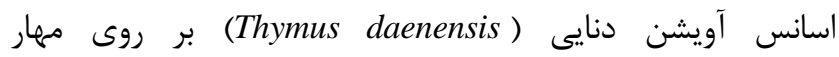

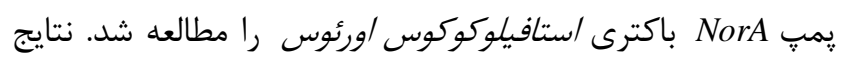

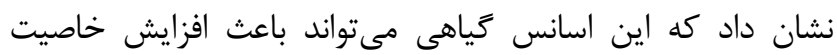

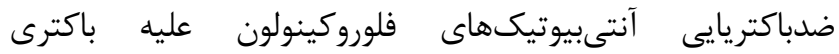

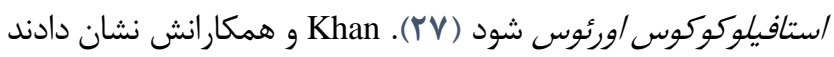

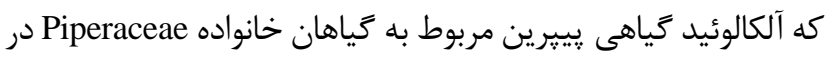
غلظت لم ميلى كرم بر ليتر باعث كاهش دو برابرى MIC باكترى

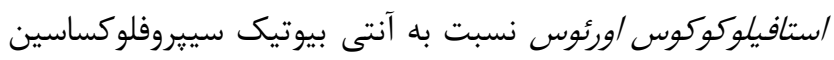

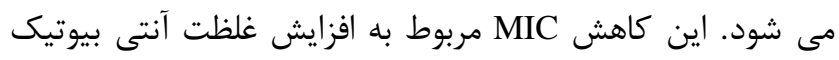

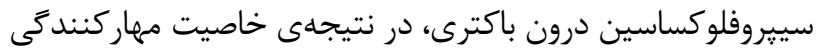

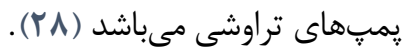

در ادامه بررسى حاضر، اثر عصاره بابونه بر فعاليت يمبهاى تراوشى سويهها داراى يمب فعال مورد بررسى قرار ترفت. مشاهده

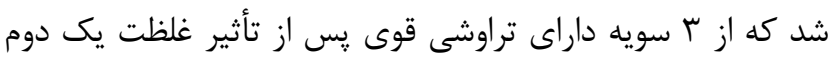

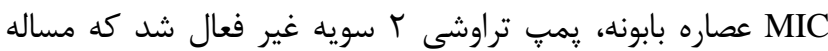

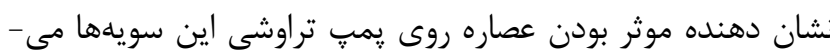

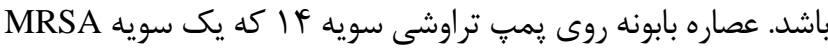

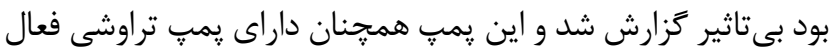
بود (شكل ץ). بررسى غلظت يك קهارم MIC عصاره بابونه، تاثيرى

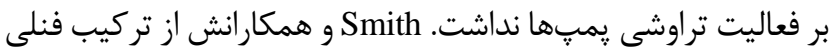

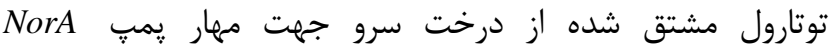

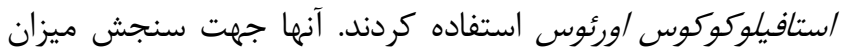
مهار يمب، از روش كاهش MIC از اتيديوم برومايد و آنتى بيوتيك فلوروكينولون در تركيب با MIC/4 توتارول استفاده كردند و در نهايت 


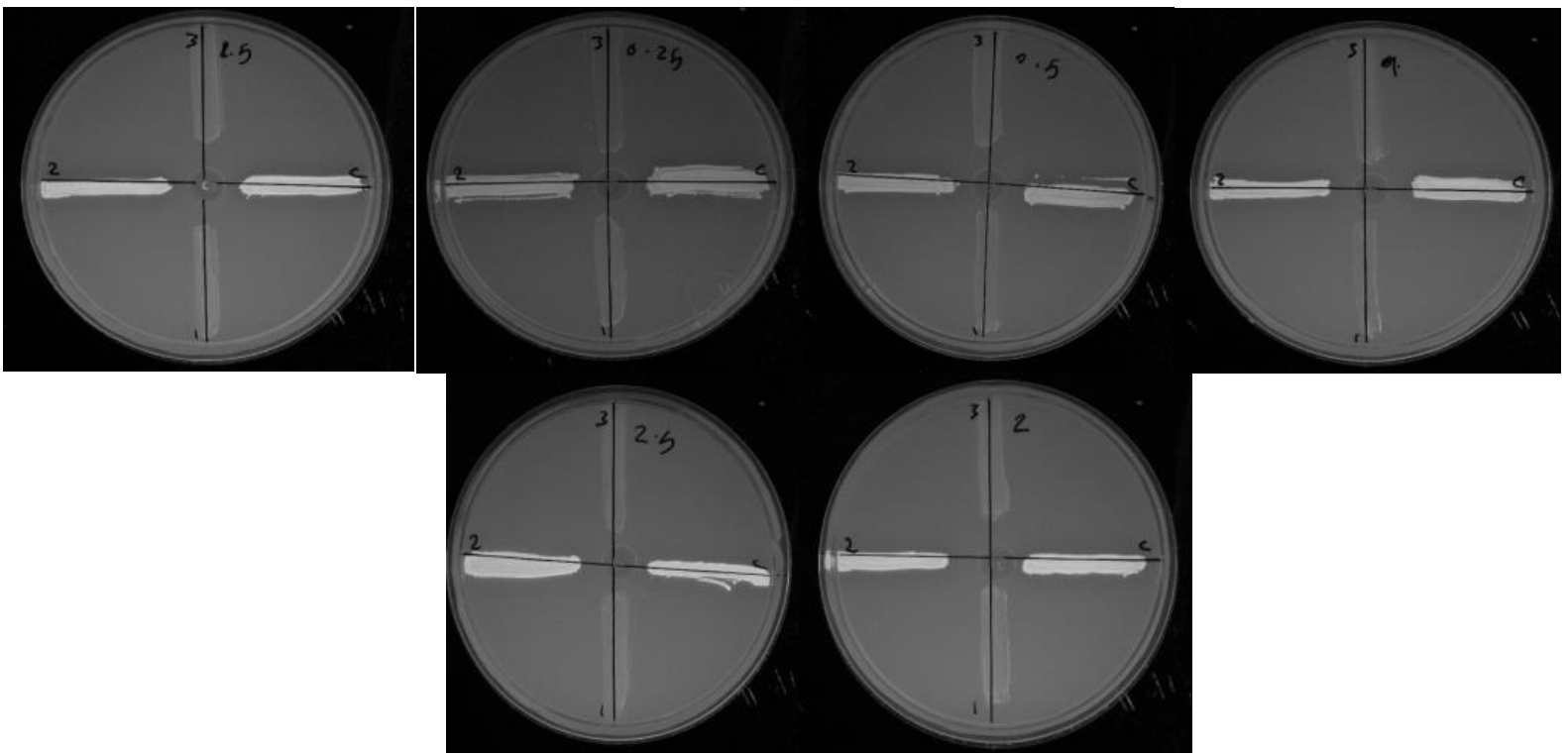

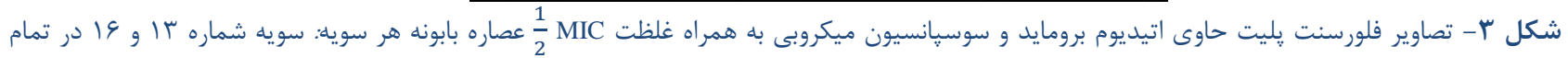

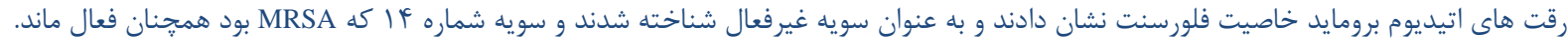

$$
\begin{aligned}
& \text { (-) به معناى عدم فعاليت ضدميكروبى است. }
\end{aligned}
$$

تكميلى جهت بررسى بيان زنوتيِى ״مبهاى تراوشى در سويههاى

استافيلوكوكوس اورئوس مقاوم به متى سيلين ييشنهاد مى شود.

$$
\text { سياسخز ارى }
$$

بدينوسيله از مسئول و كارشناسان محترم آزمايشعاه

ميكروبيولوزى دانشخاه آزاد اسلامى واحد ورامين يشيشوا و جناب آقاى اميد حسينى كارشناس آزمايشعاه جامع تحقيقاتى دانشعاه

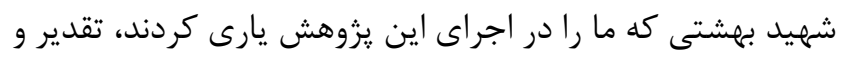
تشكر ميشود. كد اخلاق مربوط به نمونه هاى مطالعه شده IR.IAU.VARAMIN.REC.1396.3

$$
\text { بين نويسند }
$$

\section{References}

1. Imanifooladi AA, Sattari M, Peerayeh SN, Hassan ZM, Hossainidoust SR. Detection the Staphylococcus aureus producing enterotoxin isolated from skin infections in hospitalized patients. Pakistan journal of biological sciences. PJBS 2007; 10(3):502-5. [DOI:10.3923/pjbs.2007.502.505] [PMID]

2. Shahidi-Dadras M, Toossi P, Sarrafi-Rad N, Robati RM, Saeedi M, Kavand S. Staphylococcus aureus carriage in patients with psoriasis. Iranian Journal of Dermatology. 2009;12(1):1-3.

3. Jappe U. Superantigens and their association with dermatological inflammatory diseases: facts and
هالشهاى عمده اى براى يافتن ممانعت گرهاى جديد وجود دارد و با توجه به اثرات ضد ميكروبى اسانسهاى گياهى در مهار يمٍٍای تراوشى، باكترىهايى كه در ابتدا به آنتىبيوتيك ها مقاوم

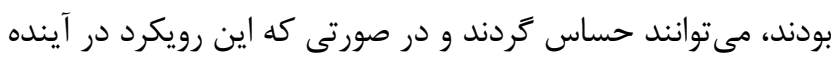
موفقيت آميز باشد، مىتواند به عنوان يك جايخزين مهرم در درمان برخى از مهمترين عفونتهاى ناشى از سويه هاى مقاوم به دارو

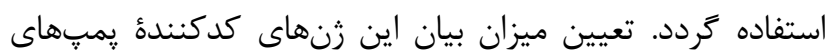
تراوشى در بين ايزولههاى فعال از نظر فنوتيبى نيز حائز اهميت است و نقش سينرزى بين پمبٍ هاى تراوشى با ساير مكانيسمهاى مقاومت

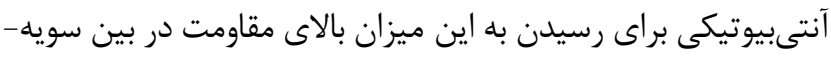
هاى /ستافيلوكوكوس /ورئوس هاى مقاوم به متى سيلين نبايد ناديده گرفته شود و به مطالعات بيشترى در اين زمينه نياز است. مطالعات

hypotheses. Acta dermato-venereologica. 2000; 80(5):321-8. [DOI:10.1080/000155500459231] [PMID]

4. Tomi NS, Kränke B, Aberer E. Staphylococcal toxins in patients with psoriasis, atopic dermatitis, and erythroderma, and in healthy control subjects. Journal of the American Academy of Dermatology. 2005; 1;53(1):67-72. [DOI:10.1016/j.jaad.2005.02.034] [PMID]

5. Webber MA, Piddock LJ. The importance of efflux pumps in bacterial antibiotic resistance. Journal of Antimicrobial Chemotherapy. 2003; 1;51(1):9-11. [DOI:10.1093/jac/dkg050] [PMID] 
6. Blanco P, Hernando-Amado S, Reales-Calderon J, Corona F, Lira F, Alcalde-Rico M, Bernardini A, Sanchez M, Martinez J. Bacterial multidrug efflux pumps: much more than antibiotic resistance determinants. Microorganisms. 2016 4(1): [DOI:10.3390/microorganisms4010014] [PMID] [PMCID]

7. Gibbons S. Phytochemicals for bacterial resistancestrengths, weaknesses and opportunities. Planta medica. 2008; 74(06):594-602. [DOI:10.1055/s2008-1074518] [PMID]

8. Stavri M, Piddock LJ, Gibbons S. Bacterial efflux pump inhibitors from natural sources. Journal of antimicrobial chemotherapy. 2006; 4;59(6):1247-60. [DOI:10.1093/jac/dkl460] [PMID]

9. Gibbons S, Oluwatuyi M, Kaatz GW. A novel inhibitor of multidrug efflux pumps in Staphylococcus aureus. Journal of Antimicrobial Chemotherapy. 2003; 1;51(1):13-7. [DOI:10.1093/ jac/dkg044] [PMID]

10. Tegos G, Stermitz FR, Lomovskaya O, Lewis K. Multidrug pump inhibitors uncover remarkable activity of plant antimicrobials. Antimicrobial agents and chemotherapy. 2002; 1;46(10):3133-41. [DOI:10.1128/AAC.46.10.3133-3141.2002] [PMID] [PMCID]

11. Pumps E, Cost F, RamA B. Efflux pumps of gramnegative bacteria: genetic responses to stress and the modulation of their activity by $\mathrm{pH}$, inhibitors, and phenothiazines. Advances in enzymology and related areas of molecular biology. 2011; 15;238:61. [DOI:10.1002/9780470920541.ch2]

12. Amaral L, Cerca P, Spengler G, Machado L, Martins A, Couto I, et al. Ethidium bromide efflux by Salmonella: modulation by metabolic energy, $\mathrm{pH}$, ions and phenothiazines. International journal of antimicrobial agents. 2011; 38(2): 140-5. [DOI:10.1016/j.ijantimicag.2011.03.014] [PMID]

13. Abdoul-Latif FM, Mohamed N, Edou P, Ali AA, Djama SO, Obame LC, Bassolé IH, Dicko MH. Antimicrobial and antioxidant activities of essential oil and methanol extract of Matricaria chamomilla L. from Djibouti. Journal of Medicinal Plants Research. 2011; 4;5(9):1512-7.

14. Charousaei F, Dabirian A, Mojab F. Using chamomile solution or a $1 \%$ topical hydrocortisone ointment in the management of peristomal skin lesions in colostomy patients: results of a controlled clinical study. Ostomy-Wound Management. 2011; $1 ; 57(5): 28$.

15. Sharifi A, Mohammadzadeh A, Mahmoodi P, Sasanian N. Inhibitory Effect of Thymus daenensis Essential Oil on Staphylococcus aureus NorA Efflux
Pump. J Adv Med Biomed Res. 2016; 24 (105) :6777

16. Martins M, McCusker MP, Viveiros M, Couto I, Fanning S, Pagès JM, Amaral L. A simple method for assessment of MDR bacteria for over-expressed efflux pumps. The open microbiology journal. 2013; 7:72. [DOI:10.2174/1874285801307010072] [PMID] [PMCID]

17. Movagharnezhad M, khataminezhad M R. Identification and Characterization of Staphylococcus aureus Methicillin and Vancomycin Resistance From Patients in Sari and Ghaemshahr Injuries and Burn Hospitals in 2015. Iran J Med Microbiol. 2018; 12 (3) :160-168 [DOI:10.30699/ijmm.12.3.160]

18. Fagheei-Aghmiyuni Z, Khorshidi A, Soori T, Moniri R, Mousavi S G A. Antibiotic susceptibility pattern and the prevalence of Staphylococcus aureus isolated from skin and soft tissue in Tehran Razi skin hospital (2014-15). Feyz. 2017; 21 (2) :188-196

19. Motamedi H, Rahmat Abadi SS, Moosavian SM, Torabi M. The Association of PantonValentine leukocidin and mecA Genes in Methicillin-Resistant Staphylococcus aureus Isolates From Patients Referred to Educational Hospitals in Ahvaz, Iran. Jundishapur J Microbiol 2015; 8(8). [DOI:10.5812/jjm.22021v2] [PMID] [PMCID]

20. Jarrahi M, Vafaei AA, Taherian AA, Miladi H, Rashidi Pour A. Evaluation of topical Matricaria chamomilla extract activity on linear incisional wound healing in albino rats. Natural product research. 2010; 10;24(8):697-702. [DOI:10.1080/14786410701654875] [PMID]

21. Roby MH, Sarhan MA, Selim KA, Khalel KI. Antioxidant and antimicrobial activities of essential oil and extracts of fennel (Foeniculum vulgare L.) and chamomile (Matricaria chamomilla L.). Industrial crops and products. 2013; 1(44):437-45. [DOI:10.1016/j.indcrop.2012.10.012]

22. Piddock LJ, Garvey MI, Rahman MM, Gibbons S. Natural and synthetic compounds such as trimethoprim behave as inhibitors of efflux in Gramnegative bacteria. Journal of Antimicrobial Chemotherapy. 2010; 19; 65(6):1215-23. [DOI:10.1093/jac/dkq079] [PMID]

23. Haddadi Zahmatkesh M A, Laripoor M, Mirzaie A, Ashrafi F. Prevalence of norA and norB efflux pump genes in clinical isolates of Staphylococcus aureus and their contribution in ciprofloxacin resistance. Iran J Med Microbiol. 2016; 10 (5) :20-30

24. Martins M, Viveiros M, Couto I, Costa SS, Pacheco T, Fanning S, Pages JM, Amaral L. Identification of efflux pump-mediated multidrug-resistant bacteria by the ethidium bromide-agar cartwheel method. in vivo. 2011; 1;25(2):171-8. 
مرداد و شهريور 1جس

|

مجلئ ميكروبشناسى يزشكى ايران

25. Patel D, Kosmidis C, Seo SM, Kaatz GW. Ethidium bromide MIC screening for enhanced efflux pump gene expression or efflux activity in Staphylococcus aureus. Antimicrobial agents and chemotherapy. 2010; 1;54(12):5070-3. [DOI:10.1128/AAC.0105810] [PMID] [PMCID]

26. Smith EC, Kaatz GW, Seo SM, Wareham N, Williamson EM, Gibbons S. The phenolic diterpene totarol inhibits multidrug efflux pump activity in Staphylococcus aureus. Antimicrobial agents and chemotherapy. 2007; 1;51(12):4480-3. [DOI:10.1128/AAC.00216-07] [PMID] [PMCID]

27. Sana M, Jameel H, Rahman M. Miracle remedy: Inhibition of bacterial efflux pumps by natural products. Journal of Infectious Diseases \& Therapy. 2015; 30. [DOI:10.4172/2332-0877.1000213]

28. Khan IA, Mirza ZM, Kumar A, Verma V, Qazi GN. Piperine, a phytochemical potentiator of ciprofloxacin against Staphylococcus aureus. Antimicrobial agents and chemotherapy. 2006; 1;50(2):810-2. [DOI:10.1128/AAC.50.2.810-812.2006] [PMID] [PMCID] 